\title{
O RETORNO DA CENTRALIDADE DO HOSPITAL PSIQUIÁTRICO: RETROCESSOS RECENTES NA POLÍTICA DE SAÚDE MENTAL
}

\author{
THE RETURN OF THE CENTRAL IMPORTANCE OF THE PSYCHIATRIC HOSPITAL: \\ RECENT RETROCESSION IN THE MENTAL HEALTH POLICY
}

Fernando Sérgio Pereira de Sousa ${ }^{1}$, Maria Salete Bessa Jorge ${ }^{2}$

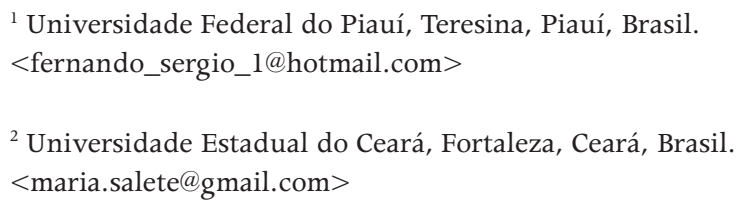

Resumo Objetivou-se compreender a experiência da convivência entre os serviços substitutivos e o hospital psiquiátrico. Trata-se de um estudo com abordagem qualitativa hermenêutica. A pesquisa foi realizada no Nordeste brasileiro. Contemplou dois cenários: Centro de Atenção Psicossocial e Hospital Psiquiátrico. Contou com 14 participantes, dos quais oito trabalhadores do Centro de Atenção Psicossocial e seis trabalhadores de saúde do Hospital Psiquiátrico. Para alcançar as informações, utilizou-se a entrevista em profundidade e a observação sistemática. A coleta ocorreu no período de agosto a outubro de 2017. A análise das entrevistas ocorreu empregando-se a hermenêutica de Paul Ricoeur, por meio das seguintes etapas: transformação dos discursos em textos, leitura exaustiva, análise estrutural, compreensão do texto de forma abrangente, interpretação e análise. Os resultados denotaram que há uma convivência paradoxal entre os serviços de atenção psicossocial e o hospitalar psiquiátrico, mesmo que o serviço hospitalar não seja reconhecido e legitimado como parte da rede de saúde mental.

Palavras-chave serviços de saúde mental; assistência à saúde; hospitais psiquiátricos.
Abstract The goal of the present study was to understand the experience of the coexistence between the substitutive services and the psychiatric hospital. This is a study with a qualitative hermeneutic approach. The research was carried out in the Northeast of Brazil. It contemplated two scenarios: Center of Psychosocial Attention, and Psychiatric Hospital. It included 14 participants, 8 of whom were workers of the Center of Psychosocial Attention and 6 who were health workers at the Psychiatric Hospital. To obtain the information, an in-depth interview and a systematic observation were performed. The collection took place from August to October 2017. The analysis of the interviews was performed using the hermeneutics of Paul Ricoeur, through the following steps: speech to text transcription, exhaustive reading, structural analysis, wide-ranging comprehension of the text, interpretation and analysis. The results showed that there is a paradoxical coexistence between the psychosocial care services and the psychiatric hospital, even though the hospital service is not recognized and legitimized as part of the mental health network.

Keywords mental health services; health assistance; psychiatric hospitals.

(cc) BY Este é um artigo publicado em acesso aberto sob uma licença Creative Commons. 


\section{Introdução}

No dia 14 de dezembro de 2017, a Comissão Intergestora Tripartite (CIT) do Sistema Único de Saúde (SUS) reuniu-se e foi aprovada, sem nenhum tipo de discussão, a resolução n. 32 (Brasil, 2017), a qual introduziu, na Rede de Atenção Psicossocial (RAPS), os ambulatórios de saúde mental e os leitos em hospitais psiquiátricos (HPs). Frente a essas recentes modificações na Política Nacional de Saúde Mental, faz-se necessário discutir 'novamente' o HP como lugar de destaque e o que era, de certa forma, invisível torna-se, agora, parte da política.

Vale ressaltar que, nos últimos 20 anos, o movimento da Reforma Psiquiátrica (RP) brasileira tem, insistentemente, colocado para a sociedade a necessidade de se abolir o hospital psiquiátrico como local de acompanhamento das pessoas com transtornos mentais, por ser alicerçado em um modelo manicomial baseado na segregação e violação de direitos.

Contrariando as recentes decisões da CIT, a portaria n. 3.088/2011 (Brasil, $2011)$ institui a RAPS e estabelece os critérios de organização e implementação em todo o país, integrando a saúde mental em todos os níveis e pontos de atenção no SUS. Outras resoluções do Ministério da Saúde, leis estaduais e a lei federal n. 10.216, de 06 de abril de 2001 também apontam firmemente para a necessidade de que a atenção à pessoa em sofrimento mental deve ocorrer, preferencialmente, em serviços extra-hospitalares, que privilegiem a não internação em hospitais psiquiátricos. Esses documentos afirmam, ainda, que os HPs devem ser, progressivamente, extintos e substituídos por serviços de bases territoriais e comunitárias (Brasil, 2011).

Logo, inserir o hospital psiquiátrico na RAPS caracteriza-se, na visão dos defensores da Reforma Psiquiátrica, um retrocesso, pois a resolução n. 32 privilegia os serviços de lógica manicomial e segregadora em detrimento de investimentos no modelo de atenção psicossocial. Além disso, estimula os dirigentes ou proprietários de hospitais psiquiátricos a manterem esses serviços abertos ao aumentar o incentivo do financiamento a esse segmento. Assim, os HPs, que deveriam ser fechados de forma progressiva, num processo de substituição por serviços territoriais, estão, paradoxalmente, na arena da RAPS.

Desse modo, defende-se, com a RP, a implantação de políticas públicas alicerçadas em valores democráticos e garantidores de direitos humanos, que fortaleçam serviços substitutivos de base territorial, com maior interlocução com a comunidade, proporcionando um curso diferente daquele atribuído à suposta 'doença mental' nas internações psiquiátricas. Esses serviços são espaços que privilegiam a geração de cuidados, de subjetividades mais autônomas e de inclusão social, os quais articulam a singularidade de cada usuário à diversidade de possibilidades de intervenções terapêuticas (Yasui, 2010). 
Fomentando a discussão, há evidências históricas, por meio de relatos e denúncias, de que as instituições psiquiátricas tradicionais, em especial os HPs, baseiam-se na tutela, na hierarquia entre trabalhadores e usuários, no afastamento dos internos em relação à sociedade. Promovem, entre outros aspectos, um processo de cronificação e institucionalização das pessoas com transtornos mentais (Basaglia, 2005).

Nesse sentido, o processo de desinstitucionalização não se refere apenas à desospitalização dos sujeitos, mas sim à construção de práticas e saberes que produzam determinadas formas de perceber, entender e de se relacionar com os fenômenos sociais e históricos. Para tanto, é preciso problematizar as bases do saber psiquiátrico e das funções sociais e políticas desempenhadas pela ciência, pelos técnicos e pelos hospitais psiquiátricos (Saraceno, 2001).

Dessa forma, este estudo pretende dar sua contribuição para o fortalecimento do processo de RP, ainda em andamento no Brasil, da construção de uma concepção dinâmica e histórica e da intervenção na saúde mental que contemple a complexidade do fenômeno saúde/doença. Isso se justifica por compreender que a convivência entre os serviços substitutivos e os hospitais psiquiátricos é algo ainda não superado e que permanece como um impasse na reversão do modelo de atenção em saúde mental brasileira.

Pitta (2011) alerta para os desafios que hoje se impõem para a RP, pois aquilo que é discutido em todo o percurso da reforma no âmbito federal, muitas vezes, não encontra acolhida em alguns governos estaduais e municipais, os quais são responsáveis por reger os dispositivos de atenção à saúde mental. A falta de incentivo de alguns governos e de seus respectivos gestores de saúde, em diferentes esferas de governo, tende a dificultar a execução de um serviço que seja promotor de vida.

Também, nesse sentido, Amarante et al. (2016) afirmam que não há como negar o perigo de retrocesso nessas conquistas da RP, especialmente com as mudanças ocorridas na coordenação nacional de saúde mental e na condução da política de atenção psicossocial no país, atualmente sob o comando dos partidos conservadores que governam o país.

Diante dessas colocações, o objetivo desta pesquisa é compreender a experiência da convivência entre os serviços substitutivos e o hospital psiquiátrico. As práticas de ambos os serviços percorrem caminhos opostos e conflitantes e, historicamente, fomentam discussões e reflexões sobre as mudanças que se processam sobre os rumos da assistência psiquiátrica, tanto no Brasil como no mundo.

\section{O desvelar dos sentidos e significados das narrativas}

Trata-se de um estudo alicerçado na abordagem qualitativa, assumindo, como arcabouço teórico, a hermenêutica de Paul Ricoeur, que tem como pre- 
ocupação central a interpretação das narrativas da experiência dos sujeitos, buscando entender os sentidos e os significados dos comportamentos de forma a interligar o texto e a ação (Ricoeur, 1989).

A pesquisa foi realizada no município de Fortaleza, capital do Ceará, cidade mais populosa do Estado e a quinta maior cidade do país. Com população estimada de 2.447.409 habitantes, é a capital de maior densidade demográfica - 7.764,6 hab $/ \mathrm{km}^{2}$. Adotou-se como cenário de estudo o Centro de Atenção Psicossocial (CAPS tipo II), localizado no distrito de saúde da Secretaria Regional IV, e o Hospital Psiquiátrico de referência do município.

A investigação contou com 14 participantes, que foram abordados diretamente pelo pesquisador nos seus respectivos centros de saúde. Na ocasião, foi explicado a cada um deles o objetivo da pesquisa e solicitado a realizarem a entrevista de maneira voluntária, assegurando-lhes o anonimato e a confidencialidade de suas narrativas. Foram assim distribuídos: oito Trabalhadores de Saúde do CAPS (enfermeiros, assistentes sociais, terapeutas ocupacionais, psicólogos e técnicos de enfermagem) e seis Trabalhadores de Saúde do HP (enfermeiros, técnicos de enfermagem, médicos, psicólogos e assistentes sociais).

Para alcançar as informações de um diferente nível de compreensão, foi utilizada a entrevista em profundidade e a observação sistemática. A coleta ocorreu no período de agosto a outubro de 2017. Houve uma aproximação com os campos empíricos e realização da investigação no CAPS e no Hospital Psiquiátrico pelo próprio pesquisador. Destaca-se que a entrevista em profundidade foi orientada por uma questão norteadora (Como se dá a atenção e o suporte assistencial às pessoas com transtornos mentais nos serviços substitutivos e no hospital psiquiátrico, tendo como eixo a articulação em rede?). No que tange à observação sistemática, foi baseada por um roteiro cujo intuito foi o de possibilitar o confronto com os dados apreendidos entre a representação (narrativas) e a prática concreta na RAPS de Fortaleza, Ceará. As anotações foram registradas em diário de campo.

Ao longo do percurso metodológico, as narrativas geradas nas entrevistas passaram por uma exaustiva leitura. Foi realizada uma primeira interpretação (naive) com o intuito de compreender o conteúdo em termos gerais e de identificar os temas principais (Caprara e Veras, 2005). Para a conformação dos grandes eixos temáticos da pesquisa, a partir do material coletado nas entrevistas, foi feita uma análise com base na hermenêutica fenomenológica de Paul Ricoeur. As anotações em diário de campo foram utilizadas como complementação aos dados analisados, oriundos das entrevistas em profundidade. Em relação ao material empírico apresentado, ressalta-se que alguns fragmentos aparecem com grifo, pois os entrevistados tiveram a oportunidade de participar da construção do texto.

Este estudo tem aderência à abordagem hermenêutica de Ricoeur, a qual propõe a elucidação do significado e o desvelamento do sentido, sedimentan- 
do uma compreensão acerca do mundo. Desse modo, optou-se por analisar os dados das narrativas dos trabalhadores da saúde mental do CAPS e do HP. Assim, a interpretação direcionou-se para as ideias centrais do texto, que são representadas pelas partes dos discursos, buscando-se compreender e revelar seus significados, ou seja, o todo em relação às partes.

Em síntese, a análise seguiu os seguintes passos: transformação dos discursos em textos; leitura simples, com o intuito do entendimento dos textos como um todo; análise estrutural, que examina o texto na sua estrutura; compreensão do texto de forma abrangente; interpretação e análise (Ricoeur, 1989).

O estudo é um recorte da tese intitulada Vozes entrelaçadas sobre a desconstrução de cronicidade em saúde mental: espaço de diálogo entre a atenção primária, especializada e hospitalar, de autoria de Fernando Sérgio Pereira de Sousa, defendida em 2017, no âmbito do Programa de Pós-Graduação em Saúde Coletiva da Universidade Estadual do Ceará. A pesquisa foi submetida à análise do Comitê de Ética em Pesquisa da Universidade Estadual do Ceará, tendo parecer favorável, sob o número 968.511/2015. Os participantes do estudo tiveram acesso ao termo de consentimento livre e esclarecido e o assinaram, assumindo o desejo de participar da pesquisa.

Para manter o anonimato dos participantes, eles foram identificados pelas letras TC, para trabalhadores da saúde do CAPS, e THP, para trabalhadores da saúde do HP, seguidas de número arábico sequencial e crescente, conforme ordem de entrevista.

\section{A convivência paradoxal entre os serviços substitutivos e os hospitais psiquiátricos}

Este estudo reflete sobre a possibilidade ou não de diálogo entre os trabalhadores do HP e do CAPS, bem como de que forma o hospital psiquiátrico faz ou não parte da rede de atenção psicossocial ao discutir a relação serviço substitutivo/hospital psiquiátrico. É válido salientar que os trabalhadores do CAPS, concordando ou não com a existência do hospital psiquiátrico, precisam manter uma relação com esses hospitais. Isso porque esses serviços existem e ainda existirão por algum tempo, no mínimo até que os serviços substitutivos sejam implantados e implementados com uma consistência mais sólida, bem como as RAPS sejam efetivas, com serviços, fluxos, ações e articulações capazes de subsidiar a necessária superação do paradigma psiquiátrico.

De acordo com o conteúdo das narrativas e a observação, seria ingênuo negar a convivência paradoxal entre a rede de atenção psicossocial e o serviço hospitalar psiquiátrico, mesmo que não seja reconhecido e legitimado como parte dessa rede de cuidados. Conforme narram os trabalhadores do CAPS: “não se pode negar a existência do hospital, (...) agora, pensar no hospital 
como rede é bastante complicado" (TC 1). Outro trabalhador do HP destaca que: “(...) nem as portarias de saúde mental do Ministério da Saúde, nem o estado e nem os trabalhadores da RAPS reconhecem o hospital psiquiátrico como serviço da rede de saúde mental" (THP 1).

Sabe-se que as condições regulamentadoras do Ministério da Saúde eram favoráveis ao trabalho proposto pela Reforma Psiquiátrica, mas nunca deixaram de contemplar, em seu interior, o hospital psiquiátrico. Assim, conforme preconizado por Prazeres e Miranda (2005), há duas constatações importantes. A primeira refere-se ao fato de que o hospital psiquiátrico é um dispositivo assistencial presente na rede de assistência em saúde mental no Brasil. A outra, de movimento inverso, é a de que o país já conta com uma rede de serviços substitutivos razoáveis, que estabelece cotidianamente sua tradição (de luta pela construção de um espaço mais solidário, mais democrático que o hospital psiquiátrico e que suporte a diferença).

Em seguimento a essa discussão, segundo se evidencia, os trabalhadores do hospital psiquiátrico narram que a existência das unidades hospitalares de cunho psiquiátrico estaria próxima da extinção. Isso porque os serviços substitutivos do município começavam a ser implantados e se afirmava, com veemência, que todos os hospitais psiquiátricos iriam fechar suas portas em um curto prazo. Essa discussão é revelada na narrativa dos trabalhadores do HP: “(...) o hospital mental fecharia suas portas em cinco anos, depois que começaram a surgir os CAPSs, e nunca fechou (...) não teve rede; (...) se defende uma rede de serviços psicossociais e substitutivos, [por isso], nunca abriu espaço de diálogo com o hospital" (THP 2).

Fica evidente a invisibilidade do hospital psiquiátrico na RAPS: não faz parte e não é reconhecido pela rede; porém, as informações empíricas revelam que é cada vez mais crescente o volume de encaminhamentos que chegam a esse serviço, solicitando avaliação psiquiátrica e leitos de internações psiquiátricas de usuários do próprio CAPS, que são encaminhados pelos profissionais desse serviço substitutivo. Relatam os trabalhadores do CAPS: "existem crises de usuários crônicos ou mesmo de pessoas que chegam em surto no CAPS, que não dá para ficar em casa e nem temos suporte no CAPS; (...) então se faz o encaminhamento para o hospital psiquiátrico" (TC 2).

De acordo com Lima et al., (2012, p. 424), “Dar conta de usuários em crise (...) tornou-se o principal desafio desse modelo substitutivo". Atualmente, trabalhadores dos CAPSs sinalizam uma mudança importante no perfil das pessoas que os buscam. Sob a vigência da política de desospitalização, indicam que, cada vez mais, as situações de crise têm aparecido, apontando a necessidade de um novo modo de organização para, com qualidade, recebêlas, cuidar delas e acompanhá-las.

Chama-se a atenção para o que está acontecendo nos CAPSs. Questões básicas, que deveriam ser realizadas nos dispositivos substitutivos, estão sen- 
do encaminhadas para o hospital psiquiátrico. Essa situação é um paradoxo, pois o CAPS tem como principal papel ordenar essa rede de atenção psicossocial e ser substitutivo ao hospital psiquiátrico, e não um 'estimulador' de demandas para a internação, que pode até ser cogitada numa rede sem uma implementação de serviços substitutivos efetivos, mas sempre pensada de forma provisória e em última instância, quando se esgotam todas as opções de cuidado territorial. Esta ideia é narrada pelos trabalhadores do HP:

\begin{abstract}
A formatação do modelo da gestão atual não tem contribuído para que o CAPS cumpra o seu papel substitutivo; (...) muitos encaminhamentos ao hospital psiquiátrico estão sendo feitos; ocorrem transferências de usuários para o hospital psiquiátrico e alguns desses usuários estão sendo encaminhados com demandas que podem ser resolvidas no CAPS e, assim, retornamos esses usuários para o CAPS com o encaminhamento [contrarreferência] informando não ter perfil para internação aqui (...) questionamos, o CAPS não deveria tratar e resolver coisas básicas? (THP 3)
\end{abstract}

Em contribuição a esse debate, Fortes (2010) cita que, no artigo $4^{\circ}$ da lei federal n. 10.216 está descrito que a internação psiquiátrica, em qualquer de suas modalidades, só será indicada quando os recursos extra-hospitalares se mostrarem insuficientes. E complementa que o código penal brasileiro e a lei federal supracitada orientam que as internações psiquiátricas ocorram em locais com características hospitalares, preservando a dignidade humana e assegurando ao usuário a humanização no atendimento, bem como sua segurança, com o menor tempo de permanência e retorno ao convívio familiar e social.

Os trabalhadores do CAPS, em suas narrativas, justificam o encaminhamento dos pacientes para os HPs pelas fragilidades e entraves que vêm ocorrendo nos processos de gestão e assistência dos dispositivos substitutivos. A falta de médicos é outro motivo e essa é a maior dificuldade enfrentada no que tange ao suporte aos usuários dos CAPSs, principalmente em momento de surto e em situações nas quais os usuários crônicos apresentam instabilidade de seu quadro clínico. Nas entrevistas obtidas para este estudo, há uma clara referência à escassez de médicos, como pode ser constatado no relato de um dos entrevistados:

Temos déficit de médicos e usuários estão [se] desestabilizando (...) e são encaminhados para os hospitais psiquiátricos; (...) dificuldades com a rede fragmentada, desarticulada e com várias problemáticas de contratação de profissionais (...) carência de profissionais (TC 3).

Tais questões atravessam o modelo de atenção à saúde médico-centrado ainda hegemônico, no qual permanece o discurso que o grande potenciali- 
zador das internações é a carência do profissional médico, até mesmo para fazer a prescrição inicial do usuário, ou dar suporte medicamentoso às pessoas com transtorno mental que chegam em crise no CAPS. Interroga-se: Será que somente a conduta médica é capaz de dar suporte ao usuário em crise, ou em situação crônica? Que outras estratégias poderiam ser utilizadas pela equipe profissional?

Segundo Machado e Santos (2013), algumas dificuldades práticas parecem contribuir para as deficiências percebidas nos serviços de saúde mental. Entre elas, o número insuficiente de equipamentos, que leva os existentes a se sobrecarregarem, com uma área de abrangência superior àquela com a qual sua capacidade operacional permite trabalhar. Há, também, reduzido número e escassa variedade de profissionais, o que limita as possibilidades de articulação de ações múltiplas e criativas. Em decorrência dessas deficiências, a que muitas vezes se soma a total inadequação da estrutura física, os serviços ficam fragilizados e, assim, impossibilitados de promover ações territoriais e integrais de cuidado, como acolhimento à crise, envolvimento da família no tratamento e estratégias de reabilitação psicossocial.

Outra justificativa para os encaminhamentos, narrada pelos trabalhadores do CAPS, é que as internações estão sendo feitas em nome da não desassistência, como pode ser percebido no relato a seguir:

Temos um compromisso ético de fazer algo por nossos usuários. Se não tenho para onde mandar ele em crise e a única opção é o hospital psiquiátrico, vou encaminhar sim para avaliação ou para possível internação, não posso deixar ninguém desassistido (TC 4).

Diante de tais acontecimentos, é preciso reconhecer que a RAPS, ora em análise, precisa rediscutir o seu posicionamento frente à Reforma Psiquiátrica em curso no município e no Brasil. Emerge a seguinte questão: A RAPS deve ou não continuar sustentada na perspectiva radical da luta antimanicomial? A pergunta justifica-se, pois a perspectiva de um hospital psiquiátrico reformulado, ou seja, um manicômio atualizado, não é uma realidade aceitável na atenção psicossocial.

Na ótica de Ferro (2009), é possível identificar, no movimento da Reforma Psiquiátrica, na contemporaneidade, dois projetos em disputa: o primeiro diz respeito ao projeto assentado na perspectiva radical da Luta Antimanicomial e no lema 'Por uma sociedade sem manicômios'. Este projeto pauta-se nos princípios que expressam um projeto societário e não apenas em um 'reformismo' da assistência psiquiátrica. O segundo projeto diz respeito a uma reforma 'simpática' aos interesses do neoliberalismo e do grande capital. Tal projeto vem aceitando a implantação da Reforma Psiquiátrica a qualquer custo e sem questionar. Tal reforma vem sendo implantada, principalmente, por meio de 
parcerias público-privadas, seja com organizações não governamentais, organizações sociais, fundações etc. Além disso, teve a inserção das comunidades terapêuticas na RAPS. A própria Rede de Cuidados teve suas ações limitadas com o do estabelecimento da portaria n. 3.088/2011 (Brasil, 2011), que instituiu a RAPS. Outras dificuldades constatadas para uma reforma psiquiátrica bem-sucedida são: a pouca expansão dos serviços substitutivos, destacando o não avanço das residências terapêuticas; a precarização das formas contratuais; o engessamento, nos últimos anos, do fechamento dos leitos em hospitais psiquiátricos em todo o Brasil.

Nesse momento, evidencia-se o ápice da preocupação com a atual RAPS no cenário pesquisado, após a emblemática narrativa de um trabalhador do CAPS: "Se não fosse esse apoio do hospital psiquiátrico, eu não sei lhe dizer como estaria a situação desse CAPS" (grifo do entrevistado) (TC 5). Essa narrativa rompe com todo um trabalho de luta construído na história da reforma psiquiátrica brasileira; viola todos os processos de avanços, pois afirma que a grande sustentação da RAPS, neste contexto estudado, está sendo efetivada pelo hospital psiquiátrico. Desse modo, configura-se a deterioração de todo um projeto coletivo de emancipação societária, ao se assumir, de maneira 'gritante', o retrocesso da RAPS e voltar ao modelo radicalmente colocado em questão, que é o manicômio.

O pesquisador corrobora com as questões evidenciadas por alguns trabalhadores do CAPS, afirmando ser 'alarmante' o discurso de considerar o HP como apoiador efetivo do serviço substitutivo, pois coloca em xeque a RAPS. Este é um ponto crítico, pois, no novo paradigma da atenção psicossocial, almeja-se prescindir da estrutura hospitalar psiquiátrica, daí o uso do termo serviços substitutivos.

Fomentando a discussão, faz-se necessário um olhar crítico sobre as próprias práticas assistenciais dos trabalhadores do CAPS, pois emerge o seguinte questionamento: Todas as possibilidades terapêuticas foram implementadas de maneira concreta, no intuito de manter o usuário sob uma atenção psicossocial? Exemplos dessas ações, que poderiam melhorar as práticas assistenciais, são: articular suporte de familiares e comunidade circunvizinha ao usuário, acompanhamento terapêutico com profissional de referência de forma intensiva, e até medicamentoso no sentido de evitar a internação, dentre outras. Como preconiza a RP, qualquer internação em hospital psiquiátrico somente será permitida no caso de não haver mais alternativas de tratamento extrahospitalar, quando forem esgotados todos os recursos de cuidado comunitários. Isso porque, vivenciar uma internação psiquiátrica excludente pode ser uma experiência desestruturante para toda a vida.

Em reforço a esse achado, como relatam Silva e Dimenstein (2014) em estudo realizado com trabalhadores de um CAPS, evidenciou-se, nos resultados, que os trabalhadores indicam um conjunto amplo de estratégias e 
recursos utilizados no manejo das situações de crise. Como exemplo dessas ações, tem-se: horário estendido; acolhimento; encaminhamento; internação psiquiátrica; intervenção medicamentosa; contenção física; cuidado intensivo; reinserção e reabilitação psicossocial; assistência domiciliar; busca ativa; ações territoriais com a Atenção Básica; suporte à família. Desse conjunto, o encaminhamento ao Serviço de Emergência Psiquiátrica (SEP) e a internação psiquiátrica, duas categorias que emergiram da produção dos dados, são propositivas de um debate que traz à tona o desafio da atenção à crise na Atenção Psicossocial.

Desse modo, observa-se uma preocupação constante dos trabalhadores do CAPS em não naturalizar a sua convivência com o HP na RAPS. Assim, outras narrativas dos trabalhadores do CAPS emergem:

Fazemos de tudo [máximo] para evitar a internação. O CAPS só encaminha para o hospital psiquiátrico os usuários em crise que já se tentou fazer todas as articulações possíveis e condutas existentes para superação e não se teve êxito; (...) a nossa maior parceria, nesse momento difícil, está sendo a ESF, os médicos das unidades estão atendendo os casos quando possível (TC 6).

Evidencia-se que esforços estão sendo feitos pelos trabalhadores dos dispositivos da RAPS no sentido de superar esse momento tão delicado de necessitar manter uma relação tão estreita com o hospital psiquiátrico, como exemplifica as narrativas dos trabalhadores do CAPS:

(...) procura-se evitar as internações e pautar nosso trabalho [no] território [e na] família. Por sua vez, recentemente, foi inaugurado na rede de saúde mental um CAPS III - 24h, com poucos leitos e ainda em fase de implementação, mas é um grande avanço para superarmos as internações psiquiátricas em hospital; (...) luta pela garantia de leitos psiquiátricos em hospitais gerais, uma luta constante e árdua que enfrentamos (TC 7).

É válido destacar que o CAPS tipo III é um ponto de atenção que compõe a RAPS e é destinado a proporcionar a atenção integral e contínua às pessoas com necessidades relacionadas a transtornos mentais que necessitem de internação, com funcionamento nas 24 horas (Brasil, 2004).

Em seguimento a essa discussão, fundamentados em argumentos, os trabalhadores do hospital relatam que os CAPSs não vêm dando conta da atenção psicossocial. Desse modo, na realidade estudada, o hospital psiquiátrico vem ganhando novamente expressão e lugar de destaque nos discursos dos trabalhadores de saúde, políticos, gestores e sociedade que ainda defendem o enclausuramento. Esse distanciamento do convívio social como forma de tratamento é pernicioso, principalmente no momento 
em que a pessoa apresenta uma situação crônica em saúde mental e se um quadro de crise psíquica. A justificativa para esse confinamento é a de que o usuário causa risco para si e para terceiros e, assim, esses atores vislumbram a internação psiquiátrica de longa permanência como a única maneira eficaz de cuidar.

É de extrema importância sinalizar, consoante à observação sistemática e às narrativas, que sempre houve - e ainda há - um ambiente de tensão e de confronto ideológico e político entre os serviços substitutivos e os hospitais psiquiátricos, configurando-se em uma disputa de sentido nessa arena política.

Dessa forma, há, na relação, um distanciamento sem espaço de diálogo, denotado nas narrativas dos trabalhadores do HP: “(...) uma certa barreira; dificuldade de diálogo, e distanciamento por questões políticas e pela radicalidade que prega a Reforma Psiquiátrica; (...) as relações ainda são bem estremecidas entre o CAPS e o hospital psiquiátrico" (THP 4).

Percebe-se que os trabalhadores do hospital psiquiátrico até admitem a importância do CAPS, porém defendem que sua existência é complementar ao hospital psiquiátrico e não substitutiva, pois a internação no hospital se faz extremamente necessária. Essas ideias são retratadas pelos trabalhadores do HP: “(...) o hospital psiquiátrico é muito necessário na internação e na crise psiquiátrica (...) se dá alta, ele vai embora, aí [é] papel do CAPS e da família acompanhar e dar continuidade ao tratamento" (THP 5).

Logo, deve-se debater essa relação de complementariedade e continuidade do tratamento das pessoas em situações crônicas na saúde mental dentro da RAPS do município. Confronta-se, então, com uma problemática: Quem complementa quem? O serviço substitutivo complementa o hospital ou viceversa? Obviamente, os dois serviços têm posições antagônicas em relação a essa questão, já que eles disputam poder.

Mas, por que falar de complementariedade do tratamento, complementariedade de serviços? Há algumas razões. Entre elas, considera-se que a mais importante é o fator de cronicidade da doença. Considerar esse fator faz com que se entenda que a possibilidade de tratamento de uma pessoa com transtorno mental vai além de um serviço e além de um único ato terapêutico. Cuidar de uma pessoa em sofrimento mental supõe a hipótese de que, a partir do primeiro ato terapêutico, ela sempre retorne para receber outro e mais outros (Prazeres e Miranda, 2005).

É interessante notar que há uma divergência e distorção nas narrativas sobre o entendimento do papel e da função do CAPS, cujo serviço é preconizado na atenção psicossocial. Como pode ser depreendido, a criação de uma rede de atenção integral à saúde mental deve ser formada por diversos dispositivos, substitutivos à lógica manicomial, tais como CAPS, internação em hospital geral, serviços residenciais terapêuticos e atenção nas unidades básicas de saúde. 
Pode-se perceber, pela observação do campo e pelas narrativas dos próprios trabalhadores do HP, práticas as quais mostram que o hospital psiquiátrico em análise sustenta um modelo manicomial:

Os medicamentos no hospital são a primeira escolha para o tratamento, (...) os pacientes chegam em crise, surto e se faz a contenção química, física (...) eles não escolhem a conduta, não têm escolha, a crise é emergencial e demanda contenção (grifo do entrevistado) (THP 6).

Ao buscar compreender o 'lugar' social que o hospital psiquiátrico ocupa na sociedade contemporânea, emergem narrativas as quais indicam que o modelo hospitalocêntrico na saúde mental se justifica. Constatam-se, nos discursos, sentimentos como medo, estigma e preconceito, enraizados no imaginário da sociedade em relação às pessoas com transtornos mentais, conforme narra o trabalhador do HP: “(...) esse lugar aqui do hospital psiquiátrico existe porque o seu olhar, o nosso olhar lá fora tem medo de tudo que é diferente!" (THP 4).

Percebe-se, historicamente, a prevalência de uma visão estigmatizada das pessoas com transtornos mentais, levando a uma exclusão social desses indivíduos, fazendo-os viver à margem da sociedade dita 'normal'. Essas pessoas são consideradas seres sem razão e sem juízo, agressivos e, por isso, perigosos e incapazes de viver em sociedade, precisando ser afastados da família e da sociedade. Ainda hoje, o tratamento é feito, sobremaneira, baseado na rotulação, pela supressão dos sintomas à base de medicamentos e pela manutenção dessas pessoas em uma instituição psiquiátrica asilar (Maciel et al., 2011).

Compondo esse imaginário estigmatizante, as pessoas em situações crônicas na saúde mental sofrem por terem suas vidas paralisadas ao experienciarem episódios constantes de internação psiquiátrica, que os afastam do convívio social, como se destaca no discurso do trabalhador do CAPS:

Um paciente mental se torna crônico por não haver um suporte social adequado, vive reinternando por motivos errados e vai encharcando o serviço e tornando crônica a sua presença, e cristaliza uma história que não deveria ser a dele e não é a dele (grifo do entrevistado) (TC 8).

Assim, essas pessoas com transtorno mental acabam por criar um universo paralelo com suas próprias regras e estruturas, que de nenhuma maneira irão se enquadrar no modelito social padronizado e engessado que não fazem o menor sentido para eles. Corroborando essa ideia, a narrativa de um trabalhador do HP é destacada: “impomos muitas regras para ser seguidas, exigimos adaptação ao que é padrão (...) isso para eles [usuários] é muito difícil. Nós, considerados normais, somos perversos (...) queremos que eles se organizem de um jeito que não faz sentido para eles" (THP 4). 
Nesse sentido, Goffman (2001) explica que, dentro das próprias instituições, os grupos de sujeitos tendem a conceber o outro a partir de estereótipos limitados e também hostis, levando ao engessamento da mobilidade social, isto é, a um distanciamento entre os dois estratos e a uma interação não intercambiável, com restrições e fronteiras no diálogo.

Consoante à observação sistemática, o hospital, ainda hoje, ocupa um lugar de abrigo e de suporte social para pessoas em situação de rua e sem laços familiares ou laços esgarçados. Pessoas que não encontram na sociedade um espaço mínimo de convivência e aceitação, tão empobrecidas de afeto e de desejos. Dessa forma, precisam se refugiar de si mesmas e acabam sendo empurradas para uma internação numa instituição psiquiátrica, pois parece essa ser a sua única oportunidade, neste contexto estudado, de se sentirem cuidadas, pois alguém disponibiliza o mínimo olhar sobre elas.

É possível compreender o processo de estigmatização a partir de estratégias da própria sociedade, que reduz as oportunidades de ação do sujeito por meio do desenvolvimento de mecanismos de controle social que extrapolam a dimensão material da repressão. Dessa forma, tanto a manipulação da informação sobre a condição do sujeito estigmatizado como outras formas simbólicas de controle acabam por sedimentar e construir cotidianamente manifestações de preconceitos e rejeições (Furtado et al., 2017).

Por isso, defende-se, neste estudo, a concepção de Reforma Psiquiátrica como um movimento para além da reorganização de serviços. Isto é, como um 'processo civilizatório', conforme expressa Sérgio Arouca, no qual a liberdade e a democracia são valores estruturantes e potencializadores do desenvolvimento do país e da sociedade brasileira. A Reforma Psiquiátrica é muito mais ampla e complexa (Zanchet et al., 2015).

A Reforma Psiquiátrica refere-se à ousadia de inventar um novo modo de cuidar do sofrimento humano, por meio da criação de espaços de produção de relações sociais pautadas por princípios e valores que buscam reinventar a sociedade, constituindo um novo lugar para o louco. Isso implica transformar as mentalidades, os hábitos e os costumes cotidianos intolerantes em relação ao diferente, buscando constituir uma ética de respeito à diferença (Yasui, 2010).

Chama-se a atenção para os trabalhadores que narram situações de sofrimento psíquico frente à 'má fama' do hospital psiquiátrico; por vezes, são hostilizados pelo fato de prestarem serviço na instituição por colegas de profissão, pelos defensores da Reforma Psiquiátrica, dentre outros. Esses profissionais expõem episódios nos quais se sentiram desrespeitados ao participarem de congressos de atenção psicossocial, no momento que se apresentavam como trabalhadores de hospitais psiquiátricos, bem como quando tentavam expressar seus pontos de vista na plenária. 
Posteriormente, foi discutida a possibilidade de uma relação dialógica entre o hospital psiquiátrico e os serviços substitutivos. Na prática, caberia a possibilidade de uma convivência pacífica, mesmo que momentânea, entre os serviços, contrariando, de certa forma, os pressupostos da RP, a qual defende a superação do hospital psiquiátrico como dispositivo de tratamento.

Na perspectiva de Amarante (2007), a Atenção Psicossocial é composta por quatro dimensões: a dimensão jurídico-política (mudanças nas legislações e portarias); dimensão teórico-conceitual (novas bases teóricas que sustentam esse campo); dimensão técnico-assistencial (novas formas de operar o cuidado em saúde mental) e a dimensão sociocultural (que é a transformação ética e política do pensamento manicomial reproduzido nas relações sociais). Esse novo campo rompe com a psiquiatria tradicional e suas bases de sustentação. Assim, discutir o relacionamento entre os serviços substitutivos e o hospital psiquiátrico é inserir na arena de debates, o 'velho' e o 'novo', enfim, a relação entre os opostos.

Mediante as narrativas dos trabalhadores do hospital psiquiátrico, constatase uma possibilidade de diálogo entre esses profissionais e os CAPSs, mesmo que as perspectivas sejam conflitantes, trazendo em si certo estranhamento.

A partir daí, fica evidente o questionamento: Como o hospital psiquiátrico, local erigido na base da exclusão social, poderia se relacionar com serviços de base territorial? Caberia aos profissionais da saúde, nesse novo momento discursivo, abrir as portas do hospital psiquiátrico e aventurar-se pelo território, respirar novos ares junto à população atendida (Ferro, 2009). Parece que não estaria presente um tamanho antagonismo entre essas duas práticas discursivas da saúde mental que impossibilitasse qualquer relação de composição.

É importante deixar claro que, na prática, essa arena de aproximação entre os referidos serviços configura-se um terreno bastante pedregoso, árido e perigoso, pois é como se estivesse deixando 'esquecida' a radicalidade da RP, que preconiza o fechamento dessas instituições hospitalares. No entanto, por que surge tal cogitação de aproximação? Potencializando a discussão, Rotelli et al. (2001) evidencia que o movimento da Psiquiatria Democrática Italiana, que se constitui em referência para a experiência da RP brasileira, lutava pela extinção progressiva dos manicômios, com a progressiva substituição destes por serviços comunitários. A ideia era a de que tais serviços rompessem com o paradigma clínico, com a relação linear de causa-efeito na concepção e tratamento da loucura, com o vínculo entre a loucura e a periculosidade. Esse movimento da Psiquiatria Democrática Italiana referia-se à necessidade de negar a instituição psiquiátrica e inventar outro modo de assistir às pessoas em sofrimento mental.

Outrossim, os CAPSs vivenciam, no momento atual, um 'sucateamento' em diversos aspectos dos seus serviços e, por isso, não estão conseguindo dar o 
suporte adequado aos usuários em situações crônicas que, muitas vezes, estão 'soltos' na rede de saúde, sem o mínimo de atenção e, assim, constantemente, entram em crise (surto), aumentando o número de demanda por internação no hospital psiquiátrico.

Desse modo, os serviços substitutivos na procura de uma solução para as dificuldades discutidas neste estudo estão no dilema de ter que encaminhar os usuários do CAPS para o hospital psiquiátrico. Pela lógica da atenção psicossocial, esses encaminhamentos deveriam ser realizados para leitos de saúde mental em hospitais gerais, que no município ora em análise são restritos e estão mais destinados a receber a demanda de usuários em uso abusivo de álcool e outras drogas, ou CAPS III. Essa atitude gera um paradoxo entre criticar e não pactuar com o modelo do hospital psiquiátrico e a solicitação do suporte hospitalar.

De acordo com o documento Saúde Mental em Dados - 12, os dados relativos aos Serviços Hospitalares de Referência em Saúde Mental, Álcool e outras Drogas e o respectivo número de leitos de saúde mental em hospital geral habilitado no período de 2012 a 2014 em cada estado brasileiro estão assim distribuídos: Centro-Oeste (49 leitos), Nordeste (72 leitos), Norte (51 leitos), Sudeste (323 leitos) e Sul (393 leitos). Esses leitos são definidos por parâmetros de cobertura, rede e diretrizes de funcionamento no contexto da atenção hospitalar da RAPS (Brasil, 2015).

É nesse paradoxo e contradição do cotidiano que talvez se possa encontrar a potência para construir caminhos de mudanças. Entretanto, conforme Bloch (2005, p. 203) alerta, “(...) no caminho para o novo, geralmente ainda que não sempre - deve-se proceder passo a passo. Nem tudo é possível e executável a qualquer hora: condições ausentes não só atrapalham como, também, chegam a impedir".

Essa relação de diálogo poderia ser pensada pela via do trabalho conjunto entre os serviços, considerando, de forma hierárquica, seus níveis de complexidade e pelo estabelecimento de uma relação que seja pautada pela autonomia das ações e respeito entre os serviços. Configurando-se não numa convivência pacífica, pois, nisto tudo quem opera o 'cuidado' versus 'descuidado' são pessoas, passíveis de paixões e afetos por ideologias e modelos assistenciais. A partir dessas 'contradições', pode-se inovar e movimentar-se para algo melhor, contudo, sem perder de vista o posicionamento central no cuidado do usuário. Como, também, poderia se criar mediadores da relação, posto que a capacidade de luta entre os dois tem limites.

Diante dessa conjuntura, propõe-se interrogar sobre a possibilidade de uma proposta contra-hegemônica, como, por exemplo, fazer com que a atenção psicossocial possa alavancar mudanças profundas num panorama nacional, no qual a política neoliberal e os modelos de gestão ainda estão centrados 
na doença. Seria possível o diálogo, o convívio entre os serviços de atenção psicossocial e os serviços hospitalares psiquiátricos? Muitos são os questionamentos e poucas as respostas; nada está dado por si só.

\section{Considerações finais}

Segundo revelou a análise das entrevistas e das observações no campo, seria ingênuo negar a convivência paradoxal entre a atenção psicossocial e o serviço hospitalar psiquiátrico, mesmo que não seja reconhecido e legitimado como parte da rede de saúde mental.

No entanto, fica evidente que é cada vez mais crescente o volume de encaminhamentos que chegam solicitando avaliação psiquiátrica e leitos de internações psiquiátricas de usuários do próprio CAPS que são encaminhados pelos profissionais desse serviço substitutivo.

Diante dos resultados, ressalta-se: o CAPS em estudo parece não conseguir funcionar numa lógica autenticamente substitutiva ao modo manicomial, já que algumas ações desenvolvidas por esse serviço não se configuram como práticas de atenção psicossocial. E em reforço a esse achado, percebeu-se, no contexto estudado, a existência de uma ideia de desmonte da rede substitutiva imposta pelo cenário político e ideológico brasileiro contemporâneo. Desse modo, o hospital psiquiátrico vem ganhando expressão e lugar de destaque nos discursos de alguns trabalhadores de saúde e de grupos de interesse da sociedade que ainda defendem o enclausuramento e o distanciamento do convívio social como forma de tratamento. Tais ações indicam que o modelo hospitalocêntrico na saúde mental se justifica, pois ainda sobressaem sentimentos de medo e estigma enraizados no imaginário da sociedade.

Cabe alertar para as distorções estabelecidas nas recentes resoluções e portarias aprovadas pelo Ministério da Saúde ao inserir o Hospital Psiquiátrico no modelo de atenção psicossocial. Há grupos de interesses fundamentalistas e neoliberais que ameaçam e atacam toda uma conjuntura de luta política e social exercida pelo processo de democratização histórico da Reforma Psiquiátrica brasileira.

Como pode ser depreendido, o estudo demonstra que esforços estão sendo feitos pelos trabalhadores dos dispositivos da RAPS no sentido de superar a manutenção da necessidade de uma relação constante com o hospital psiquiátrico.

Contudo, o campo da saúde mental, apesar de experimentar avanços ao vivenciar novas experiências impulsionadas pela Reforma Psiquiátrica, o cenário em análise é ainda alicerçado num modelo de atenção médico-centrado hegemônico, em que os serviços substitutivos de atenção psicossocial não vêm conseguindo dar o suporte efetivo às pessoas com transtorno mental na RAPS, configurando práticas que, paradoxalmente, têm potencializado as in- 
ternações psiquiátricas e a permanência do hospital psiquiátrico como lugar de cuidado em saúde mental.

Por fim, vale destacar que o estudo ora apresentado expõe limitações, por ser focado nas narrativas expressas pelo olhar apenas dos trabalhadores de saúde dos cenários estudados. Dessa forma, faz-se necessário o aprofundamento da discussão da temática aqui levantada ao se mergulhar em novas pesquisas que tragam para a arena do debate os usuários, seus familiares e os formuladores de políticas. Do mesmo modo, é imperioso ouvir o movimento de resistência estabelecido na conjuntura atual da saúde mental - em oposição ao que se evidencia como mudança ao instituído.

\section{Colaboradores}

Fernando Sérgio Pereira de Sousa responsabilizou-se pela elaboração da pesquisa, coleta de dados, análise das informações, redação e formatação do artigo. Maria Salete Bessa Jorge, pela elaboração da pesquisa, orientação e revisão crítica do artigo. Os autores declaram não ter conflitos de interesse.

\section{EL RETORNO DE LA CENTRALIDAD DEL HOSPITAL PSIQUIÁTRICO: RETROCESOS RECIENTES EN LA POLÍTICA DE SALUD MENTAL}

Resumen Se ha intentado comprender la experiencia de la convivencia entre los servicios substitutivos y el hospital psiquiátrico. Se trata de un estudio con abordaje cualitativo hermenéutico. La encuesta fue realizada en el Nordeste brasileño. Contempló dos escenarios: Centro de Atención Psicosocial y Hospital Psiquiátrico. Contó con 14 participantes, de los cuales ocho trabajadores del Centro de Atención Psicosocial y seis trabajadores de la salud del Hospital Psiquiátrico. Para alcanzar las informaciones, se utilizó la entrevista en profundidad y la observación sistemática. La obtención ocurrió en el período de agosto a octubre de 2017. El análisis de las entrevistas se realizo empleándose la hermenéutica de Paul Ricoeur, por medio de las siguientes etapas: transformación de los discursos en textos, lectura exhaustiva, análisis estructural, comprensión del texto de forma total, interpretación y análisis. Los resultados denotaron que hay una convivencia paradoxal entre los servicios de atención psicosocial y el hospitalario psiquiátrico, aunque el servicio hospitalario no sea reconocido y legitimado como parte de la red de salud mental.

Palavras clave sentido de comunidad; promoción de la salud; salud ocupacional. 


\section{Referências}

AMARANTE, Paulo et al. Derechos humanos y salud mental en Brasil: una historia de lucha y militancia por la justicia social y el derecho a la vida: "la salud no se vende, la locura no se encierra". Átopos: Salud Mental, Comunidad y Cultura, Madrid, n. 2, p. 1-16, 2016.

AMARANTE, Paulo. Saúde mental e atenção psicossocial. Rio de Janeiro: Editora Fiocruz, 2007.

BASAGLIA, Franco. A destruição do hospital psiquiátrico como lugar de institucionalização: mortificação e liberdade do "espaço fechado". In: AMARANTE, Paulo (org.). Escritos selecionados em saúde mental e reforma psiquiátrica. Rio de Janeiro: Garamond. 2005. p. 23-34.

BLOCH, Ernst. O princípio esperança. v. 1. Rio de Janeiro: Contraponto; Editora da Uerj, 2005.

BRASIL. Ministério da Saúde. Comissão Intergestores Tripartite. Resolução n. 32, de 14 de dezembro de 2017. Brasília, 2017. Disponível em: <http://portalms.saude.gov.br/noticias/ agencia-saude/42176-saude-mental-vetaampliacao-de-leitos-psiquiatricos-em-hospitaisespecializados-e-amplia-rede-de-assistencia > . Acesso em: 20 dez. 2017.

BRASIL. Ministério da Saúde. Lei n. 10.216, de 6 de abril de 2001. Dispõe sobre a proteção e os direitos das pessoas portadoras de transtornos mentais e redireciona o modelo assistencial em saúde mental. Diário Oficial [da] República Federativa do Brasil, Brasília, DF, Poder Executivo, 6 abr. 2001. Disponível em: <http://www.planalto.gov.br/ccivil_03/ LEIS/LEIS_2001/L10216.htm>. Acesso em: 17 dez. 2017.

BRASIL. Ministério da Saúde. SAS/DAPES. Coordenação Geral de Saúde Mental, Álcool e Outras Drogas. Saúde Mental em Dados 12, Brasília, ano 10, n. 12, out. 2015. Informativo eletrônico de dados sobre a Política Nacional de Saúde Mental. 48p. Disponível em: < http:// www.mhinnovation.net/sites/default/files/
downloads/innovation/reports/Report_12edicao-do-Saude-Mental-em-Dados.pdf $>$. Acesso em: 25 mar. 2018.

BRASIL. Ministério da Saúde. Secretaria de Atenção à Saúde. Departamento de Ações Programáticas Estratégicas. Saúde mental no SUS: os centros de atenção psicossocial. Brasília, 2004. Disponível em: <http://www. ccs.saude.gov.br/saude_mental/pdf/sm_sus. pdf $>$. Acesso em: 13 dez. 2016.

BRASIL. Portaria n. 3.088, de 23 de dezembro de 2011. Institui a Rede de Atenção Psicossocial para pessoas com sofrimento ou transtorno mental e com necessidades decorrentes do uso de crack, álcool e outras drogas, no âmbito do Sistema Único de Saúde (SUS). Diário Oficial [da] República Federativa do Brasil, Poder Executivo, Brasília, DF, 25 maio 2013. Seção 1, p. 59- 61 .

CAPRARA, Andrea; VERAS, Maria S. C. Hermenêutica e narrativa: a experiência de mães de crianças com epidermólise bolhosa congênita, Brasil. Interface: Comunicação, Saúde, Educação, Botucatu, v. 9, n. 16, p. 131-146, 2005.

FERRO, Luís F. Trabalho territorial em hospitais psiquiátricos: construindo no presente um futuro sem manicômios. Psicologia: Ciência e Profissão [on line], Brasília, v. 29, n. 4, p. 752-767, 2009. Disponível em: <http://dx.doi. org/10.1590/S1414-98932009000400008>. Acesso em: 20 dez. 2017.

FORTES, Hildenete M. Tratamento compulsório e internações psiquiátricas. Revista Brasileira de Saúde Materno Infantil, Recife, v. 10, supl. 2, 2010. Disponível em: <http:// www.scielo.br/scielo.php?script=sci_arttex t\&pid=S1519-38292010000600009 > . Acesso em: 26 set. 2017.

FURTADO, Roberto P. et al. Desinstitucionalizar o cuidado e institucionalizar parcerias: desafios dos profissionais de Educação Física 
dos CAPS de Goiânia em intervenções no território. Saúde e Sociedade, São Paulo, v. 26, n. 1, p. 183-195, 2017.

GOFFMAN, Erving. Manicômios, prisões e conventos. São Paulo: Perspectiva, 2001.

LIMA, Mônica et al. Signos, significados e práticas de manejo da crise em Centro de Atenção Psicossocial. Interface: Comunicação, Saúde e Educação, Botucatu, v. 16, n. 41, p. 423-434, 2012.

MACHADO, Vanessa; SANTOS, Manoel A. O tratamento extra-hospitalar em saúde mental na perspectiva do paciente reinternado. Psicologia em Estudo, Maringá, v. 18, n. 4, p. 701-712, 2013.

MACIEL, Silvana C. et al. Representações sociais de familiares acerca da loucura e do hospital psiquiátrico. Temas em Psicologia [on line], Ribeirão Preto, v. 19, n. 1, p. 193-204, 2011.

PITTA, Ana M. F. Um balanço da reforma psiquiátrica brasileira: instituições, atores e políticas. Ciência \& Saúde Coletiva, Rio de Janeiro, v. 16, n. 12, p. 4.579-4.589, 2011.

PRAZERES, Paulo S.; MIRANDA, Paulo S. C. Serviço substitutivo e hospital psiquiátrico: convivência e luta. Psicologia: Ciência e Profissão, Brasília, v. 25, n. 2, p. 198-211, 2005.
RICOEUR, Paul. Do texto à ação: ensaios de hermenêutica II. (tradução de Alcino Cartaxo e Maria José Sarabando). Porto: Rés., p. 163-183, 1989.

RICOEUR, Paul. Interpretação e ideologias. 4. ed. Rio de Janeiro: Francisco Alves, 1990.

ROTELLI, Franco et al. Desinstitucionalização, uma outra via. In: NICÁCIO, F. (org.) Desinstitucionalização. 2. ed. São Paulo: Hucitec, 2001.

SARACENO, Benedetto. Reabilitação psicossocial: uma prática à espera de teoria. In: PITTA, Ana M. F. (Ed.). Reabilitação psicossocial no Brasil. São Paulo: Hucitec, 2001. p. 150-154.

SILVA, Maura L. B.; DIMENSTEIN, Magda D. B. Manejo da crise: encaminhamento e internação psiquiátrica em questão. Arquivos Brasileiros de Psicologia, Rio de Janeiro, v. 66, n. 3, p. 31-46, 2014.

YASUI, Silvio. Rupturas e encontros: desafios da reforma psiquiátrica brasileira. Rio de Janeiro: Editora Fiocruz, 2010.

ZANCHET, Lívia et al. "Receituário mais que especial": uma intervenção urbana para pensar arte e pesquisa no contexto da Reforma Psiquiátrica. Interface: Comunicação, Saúde e Educação, Botucatu, v. 19, n. 55, p. 1.0391.050, 2015. 